\title{
Prevalence and Radiological Evaluation of Lumbar Spondylosis on Magnetic Resonance Imaging
}

\author{
Maha Munir Mir ${ }^{*}$, Akash John ${ }^{2}$, Muhammad Ahmad Naeem ${ }^{3}$, Hussnain Rashid Butt ${ }^{4}$, Abid Ali $^{5}$ \\ ${ }^{1,4}$ Medical Imaging Doctor, Department of Radiology Sciences and Medical Imaging, The University of Lahore, Gujrat, Pakistan \\ ${ }^{2,3}$ Lecturer, Department of Radiology Sciences and Medical Imaging, the University of Lahore, Gujrat Pakistan \\ ${ }^{5}$ Associate Professor, Department of Allied Health Sciences, the University of Lahore, Gujrat, Pakistan
}

\begin{abstract}
Article History
Received: 28.02 .2021

Accepted: 29.03.2021

Published: 14.04.2021

Journal homepage:

https://www.easpublisher.com

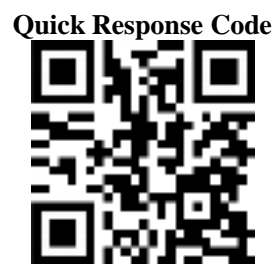

Abstract: Background: Low back pain is most common complaint in majority of population. It is important to preclude its serious cause which disturbs quality of life and results in disability. Due to soft tissue detail study Magnetic Resonance Imaging is the emerging modality and used to evaluate intervertebral disk changes and spine pathologies. Objectives: To estimate the association of lower back pain with lumbar spondylosis in determination to the patterns of lumbar disc degeneration on Magnetic Resonance Imaging. Methodology: A cross sectional and observational study of 80 patients with low back pain who were prescribed lumbosacral MRI was held. All were evaluated on magnetic resonance imaging to investigate the underlying cause of low back pain along with various MRI features of lumbar spine degeneration. Result: Majority of the patients had low back pain 87.7\%. Different lumbar spondylosis patterns evaluated on MRI were lumbar disk degeneration $80.2 \%$, disc dehydration $51.9 \%$ while endplate changes were $28.4 \%$. Other patterns such as anterior osteophytes hypertrophy of ligament flavum, facet joint arthrosis and disc bulges were evaluated. Spondylolisthesis was rare while herniation of disk and disk bulges were frequently seen at lumbar spine level of L4-L5 (50.6\%). Conclusion: Lower back pain with progressing age of 45 years and above is common in lumbar spondylosis. Magnetic resonance imaging is modality of choice and has set the benchmark to detect different patterns of lumbar spondylosis including disk degeneration and other disc pathologies.

Keywords: Low Back Pain, Lumbar spondylosis, lumbar disk degeneration, MRI.
\end{abstract}

Copyright ( 2021 The Author(s): This is an open-access article distributed under the terms of the Creative Commons Attribution 4.0 International License (CC BY-NC 4.0) which permits unrestricted use, distribution, and reproduction in any medium for non-commercial use provided the original author and source are credited.

\section{INTRODUCTION}

World is confronting the issues of spine which is getting critical and also becoming a serious clinical issue and Spondylosis is one of them [1]. It is an agerelated degenerative condition that diffusely upsets the spinal segment basically the cervical and lumbar spine [2]. Lumbar spondylosis and lumbar osteoarthritis is notable phrasings used for degeneration of lumbar spine [3].

Spondylosis of lumbar spine is a disorder that comprises a wide spectrum of conditions involving degeneration of intervertebral disc or facet joints, formation of bony spurs(osteophytes), vertebral body or endplate sclerosis, hypertrophy of ligaments or in great seriousness causes narrowing of spinal line or discspace and may cause disability [4, 5]. Lumbar spondylosis is a musculoskeletal issue and is one of the significant reasons of physical weakening in old age people [6]. The degeneration of lumbar spine can be symptomatic and asymptomatic $[7,8]$.
Low back pain is an immensely realized general medical problem [9] that large part of people almost two-third [10] or $80 \%$ [3]] individuals experience in their life time. It is the most well-known clinical symptom of lumbar spondylosis. Low back pain is extremely normal issue which may has various factors behind its etiology. In majority of people $90 \%$, it may go off within 6 weeks but almost $15-45 \%$ people in a population suffers from chronic pain at low back that continues for more than 3 months and causes serious impression on the quality of life. Lumbar spondylosis which is a disk degenerative disorder can be the cause of low back pain [11]. Lumbar spondylosis is when symptomatic, it is additionally present with different indications of sensory or motor dysfunction in lower extremities, pain radiating towards hip or legs mostly sciatica [8] especially in young individuals [12] Changes in sphincter capacity such as neurogenic bladder or neurologic loss can be the aftereffect of spinal cord compression from extreme degeneration of lumbar spine. Neurogenic claudication is the extreme condition that happens because of lumbar spinal 
stenosis which generally occurs in individuals with constant lumbar spondylosis [2]. Lumbar spondylosis is generally asymptomatic. LS can start in asymptomatic individuals of 20 years.

Some of the risk factors that purposely go with the lumbar spondylosis and cause disc degeneration include age, sex, gender, BMI, hypertension, smoking, diabetes, joint inflammation, trauma, weight lifting and manual work $[4,13]$. It is likewise seen that people with long lasting lumbar spondylosis or disc degeneration causes lumbar kyphosis. Chronic lumbar degenerative disease disturbs and restricts the daily life activities [14].

For the diagnosis of lumbar degenerative disease procedure of taking previous history, physical examination, imaging studies are performed. For radiological assessment of lumbar disk degeneration or lumbar spondylosis different modalities for imaging are used [13]. X-rays are the first line of evaluation whereas; CT and MRI are modalities for detailed investigation. Magnetic resonance imaging now act as a backbone to investigate the reason of lower back pain because of owning magnificent soft tissue detail, cross sectional ability and absence of harmful rays [8, 15]. Therefore, with advancement MRI is now considered as an ideal, accurate and reliable modality for the assessment and evaluation of lumbar spondylosis which involves features of degenerative disk disease, degenerative endplate changes, disk herniation, spinal compression and consequences of instability in degenerative lumbar spondylosis $[5,10]$. The vertebral column and intervertebral disc space are accessible by magnetic resonance imaging. Another advantage of MRI is that it permits the coordinate assessment of structures that passes through spinal column along with the structure of vertebral disk. CT does not give this direct evaluation. On MRI images, diagnosis of desiccated vertebral disks and lumbar spondylosis is made by changes in the signal intensity of vertebral body end plate [13]

\section{Material ANd Methods}

The current study was conducted in Department of Radiology of Private Sector Hospital in Gujranwala, Pakistan. The study was held during the period of six months from August 2020 to January 2021. It was a cross-sectional and observational study. Eighty individuals were evaluated on MRI machine with strength of $1.5 \mathrm{~T}$. Images were obtained on standardized axial T2 weighted, sagittal T1 and T2W sequences.T2W sagittal sequence provided the demonstrative data. Compiled interpretation of all three sequences was recorded in the final report. For the evaluation of disk herniation each of the five intervertebral disk levels of lumbar spine was evaluated. While adding more into this, some findings which were assessed for their presence or absence are as follows: annular disc tear, disc height loss, disc dehydration and nerve root encroachment. Verbal consent from all participating patients was taken and their history was noted. Permission was granted by the ethical committee of our institute.

\section{INCLUSION CRITERIA}

Demographic findings of 80 patients between ages 30 to 80 years with low back pain advised for lumbosacral spine MRI were encompassed and included in this study.

\section{ExCLUSION CRITERIA}

Individuals suffered from recent trauma, spinal injury or infection, malignancy, pregnancy, involvement of cervical spine and patients with previous history of surgery were excluded.

\section{Statistical Analysis}

Table-1

\begin{tabular}{|l|l|r|r|r|r|}
\hline \multicolumn{7}{|c|}{ Is Low back pain present } \\
\hline \multirow{3}{*}{ Valid } & & Frequency & Percent & Valid Percent & Cumulative Percent \\
\hline & No & 13 & 16.2 & 16.2 & \\
\cline { 2 - 7 } & Yes & 67 & 83.8 & 83.8 & 16.2 \\
\cline { 2 - 7 } & Total & 80 & 100.0 & 100.0 & 100.0 \\
\hline
\end{tabular}




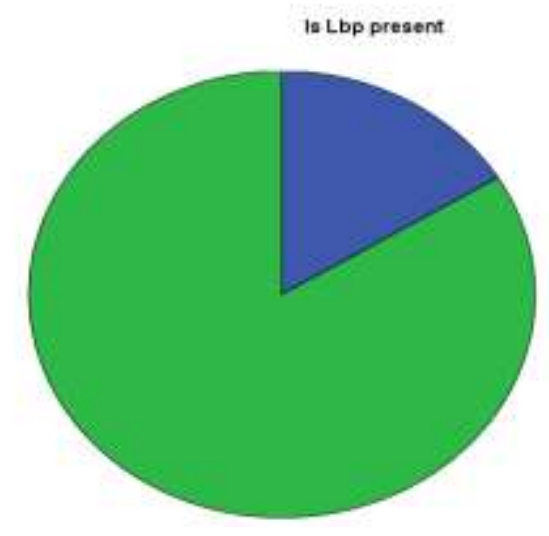

${ }_{m}^{\prime}$

Table 2

Is Lumbar disc degeneration present

\begin{tabular}{|r|r|r|r|r|}
\hline & Frequency & Percent & \multicolumn{1}{|c|}{$\begin{array}{c}\text { Valid } \\
\text { Percent }\end{array}$} & $\begin{array}{c}\text { Cumulative } \\
\text { Percent }\end{array}$ \\
\hline Valid No & 15 & 18.8 & 18.8 & 18.8 \\
Yes & 65 & 81.2 & 81.2 & 100.0 \\
Total & 80 & 100.0 & 100.0 & \\
\hline
\end{tabular}

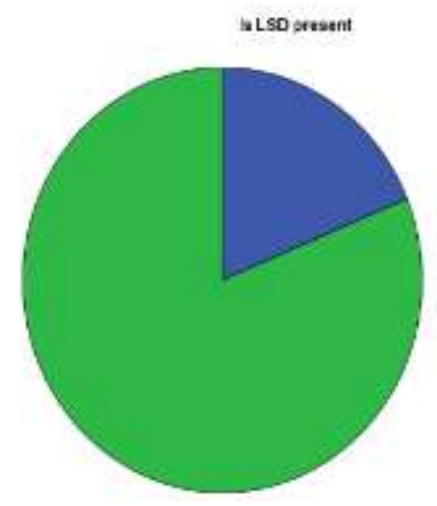

Table 3

\section{Is Endplate changes present}

\begin{tabular}{|r|r|r|r|r|}
\hline & Frequency & Percent & Valid Percent & $\begin{array}{c}\text { Cumulative } \\
\text { Percent }\end{array}$ \\
\hline Valid NO & 57 & 71.2 & 71.2 & 71.2 \\
Yes & 23 & 28.8 & 28.8 & 100.0 \\
Total & & & & \\
& & 100.0 & 100.0 & \\
\hline
\end{tabular}

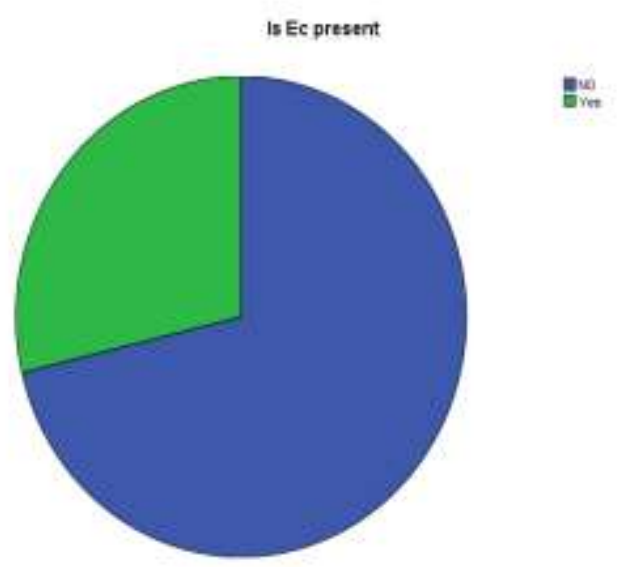




\section{Table-4}

Is Anterior osteophytes Present

\begin{tabular}{|r|r|r|r|r|}
\hline & Frequency & Percent & \multicolumn{1}{|c|}{$\begin{array}{c}\text { Valid } \\
\text { Percent }\end{array}$} & $\begin{array}{c}\text { Cumulative } \\
\text { Percent }\end{array}$ \\
\hline Valid No & 70 & 87.5 & 87.5 & 87.5 \\
Yes & 10 & 12.5 & 12.5 & 100.0 \\
Total & 80 & 100.0 & 100.0 & \\
\hline
\end{tabular}

Table-5 and table 6

\section{Is Facet Joint Arthrosis present}

\begin{tabular}{|r|r|r|r|r|}
\hline & Frequency & Percent & \multicolumn{1}{|c|}{$\begin{array}{c}\text { Valid } \\
\text { Percent }\end{array}$} & $\begin{array}{c}\text { Cumulative } \\
\text { Percent }\end{array}$ \\
\hline Valid No & 58 & 72.5 & 72.5 & 72.5 \\
Yes & 22 & 27.5 & 27.5 & 100.0 \\
Total & 80 & 100.0 & 100.0 & \\
\hline
\end{tabular}

IE F.AA present

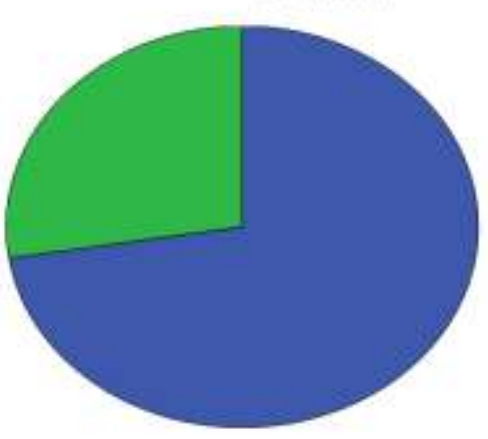

.

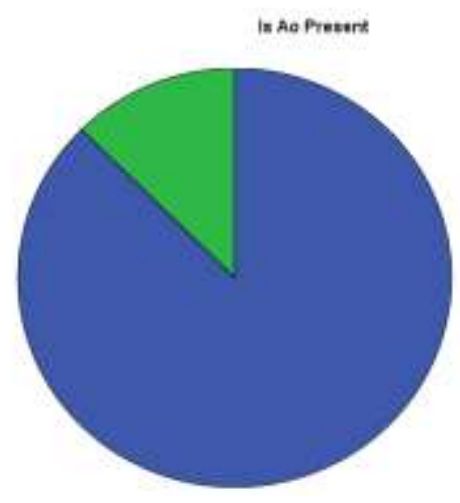

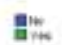

\section{Is Hypertrophy of Ligamentum flavum present}

\begin{tabular}{|r|r|r|r|r|}
\hline & Frequency & Percent & Valid Percent & $\begin{array}{c}\text { Cumulative } \\
\text { Percent }\end{array}$ \\
\hline Valid No & 50 & 62.5 & 62.5 & 62.5 \\
Yes & 30 & 37.5 & 37.5 & 100.0 \\
Total & 80 & 100.0 & 100.0 & \\
\hline
\end{tabular}

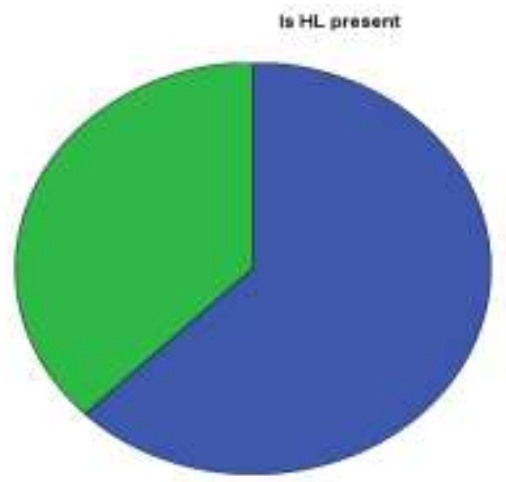

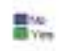

Table 7

\section{Is Disk dehydration present}

\begin{tabular}{|r|r|r|r|r|}
\hline & Frequency & Percent & \multicolumn{1}{|c|}{$\begin{array}{c}\text { Valid } \\
\text { Percent }\end{array}$} & $\begin{array}{c}\text { Cumulative } \\
\text { Percent }\end{array}$ \\
\hline Valid NO & 38 & 47.5 & 47.5 & 47.5 \\
Yes & 42 & 52.5 & 52.5 & 100.0 \\
Total & 80 & 100.0 & 100.0 & \\
\hline
\end{tabular}

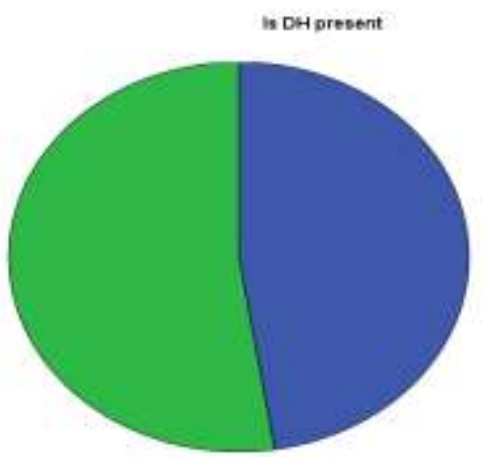


Table-8 and table-9

\section{Is Spondylolisthesis present}

\begin{tabular}{|r|r|r|r|r|}
\hline & Frequency & Percent & \multicolumn{1}{|c|}{$\begin{array}{c}\text { Valid } \\
\text { Percent }\end{array}$} & $\begin{array}{c}\text { Cumulative } \\
\text { Percent }\end{array}$ \\
\hline Valid No & 66 & 82.5 & 82.5 & 82.5 \\
Yes & 14 & 17.5 & 17.5 & 100.0 \\
Total & 80 & 100.0 & 100.0 & \\
\hline
\end{tabular}

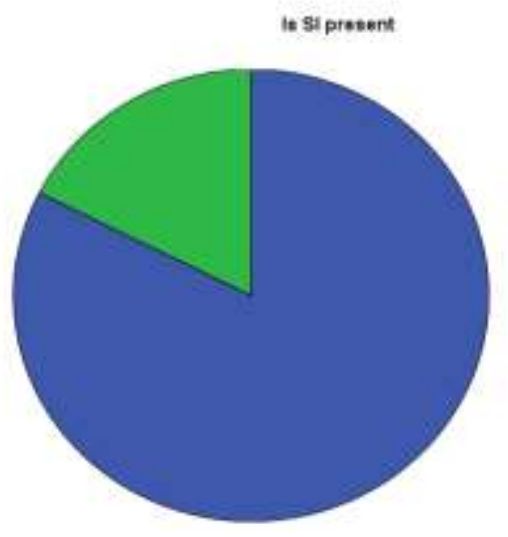

ㅂ.ing.

Table 10

\section{Level of the disc}

\begin{tabular}{|r|r|r|r|r|}
\hline & Frequency & Percent & Valid Percent & $\begin{array}{c}\text { Cumulative } \\
\text { Percent }\end{array}$ \\
\hline Valid L1-L2 & 8 & 10.0 & 10.0 & 10.0 \\
L2-L3 & 7 & 8.8 & 8.8 & 18.8 \\
L3-L4 & 5 & 6.2 & 6.2 & 25.0 \\
L4-L5 & 41 & 51.2 & 51.2 & 76.2 \\
L5-S1 & 19 & 23.8 & 23.8 & 100.0 \\
Total & 80 & 100.0 & 100.0 & \\
\hline
\end{tabular}

Is Disk Bulge present

\begin{tabular}{|r|r|r|r|r|}
\hline & Frequency & Percent & \multicolumn{1}{|c|}{$\begin{array}{c}\text { Valid } \\
\text { Percent }\end{array}$} & $\begin{array}{c}\text { Cumulative } \\
\text { Percent }\end{array}$ \\
\hline Valid No & 32 & 40.0 & 40.0 & 40.0 \\
Yes & 48 & 60.0 & 60.0 & 100.0 \\
Total & 80 & 100.0 & 100.0 & \\
\hline
\end{tabular}

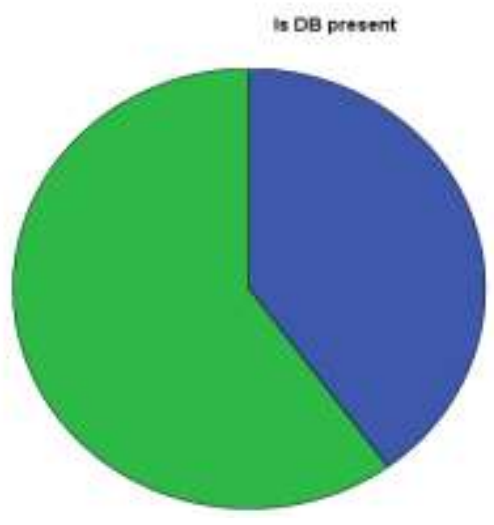

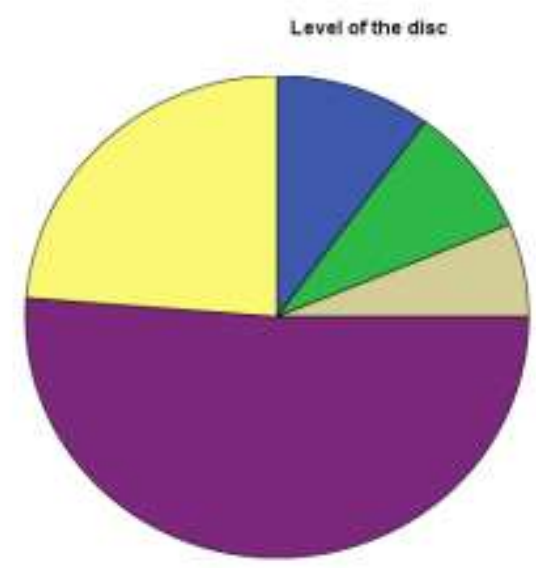


Table-11

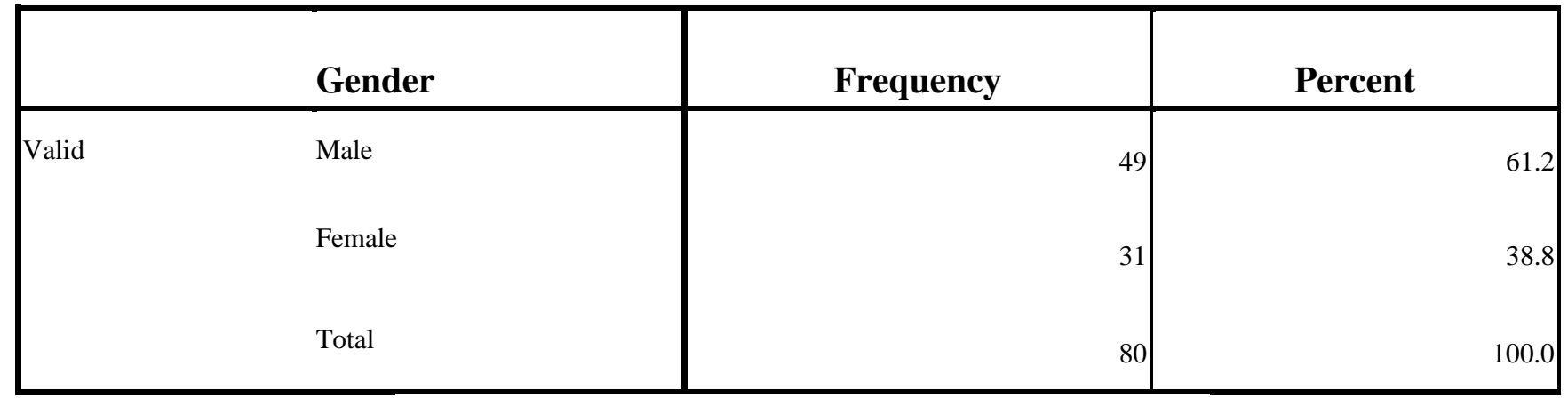

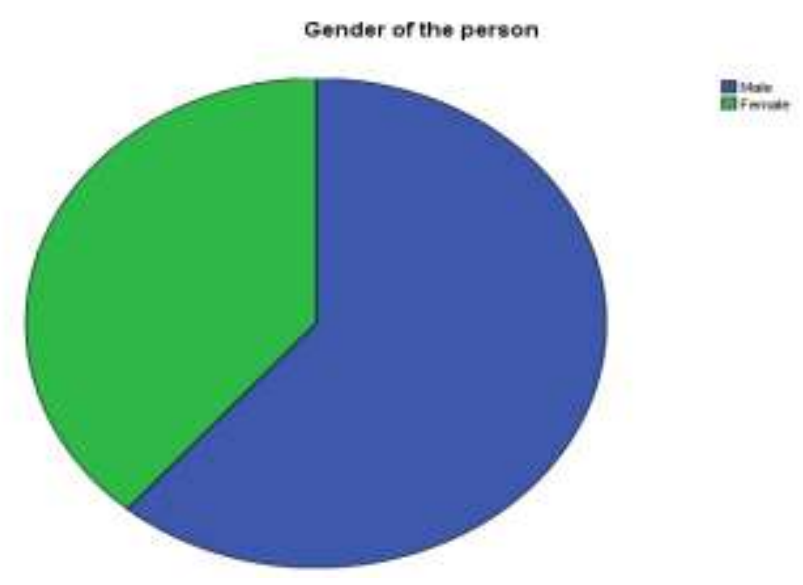

Table 12

\begin{tabular}{l|r|r|}
\hline Age & Frequency & \multicolumn{1}{|c|}{ Percent } \\
\hline $30-40$ & 17 & 21.2 \\
$41-50$ & 20 & 25.0 \\
$51-60$ & 10 & 12.5 \\
$61-70$ & 19 & 23.8 \\
$71-80$ & 14 & 17.5 \\
Total & 80 & 100.0 \\
\hline
\end{tabular}

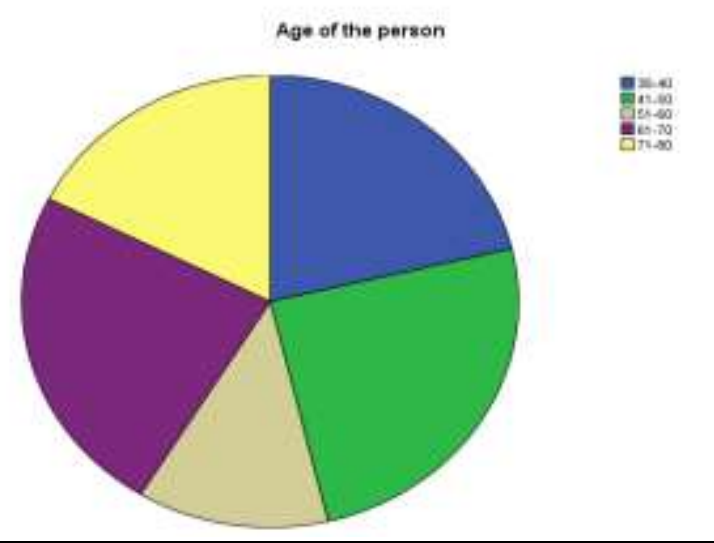




\section{RESULTS}

In this research 80 patients with lower back pain were taken into account. Findings noted on Magnetic Resonance Imaging that are indicative of lumbar spondylosis are: hypertrophy of the ligamentum flavum, modic (endplate) changes, arthrosis of facet joint, formation of the bony spurs(osteophytes), bulging of disk.

Table*1 demonstrates the presence of lower backache. Out of 80 patients LBP is present in 67 and its percentage was $83.8 \%$ whereas, it is not present in 13 patients and its percentage is $16.2 \%$. Pie chart of LBP shows its high prevalence among patients. On other hand, the Lumbar spine degeneration was frequent in 65 patients with percentage of 81.2 and it is absent in 15 patient whose percentage is 18.8 . It is shown in table*2. Apart from this table*3 demonstrates that endplate changes are present in 23 patients $(28.8 \%)$ and absent in 57 patient that makes $71.2 \%$. patients having lumbar spine degeneration reported theses abnormalities. Table*4 presents that the anterior osteophytes are present in 10 patient whose percentage is 12.5 while it is not present in 70 patient whose percentage is about 87.5. Whereas, the presence of facetal joint arthrosis is about $27.5 \%$ and is absent in 58 patients that makes percentage of about 72.5 shown in table*5

Table*6: Another MRI finding named hypertrophy of ligamentum flavum is present in 30 patients and its percentage is about 37.5 and it is not present in 50 patients whose percentage is 62.5 . Table*7: shows Most common feature which is disc dehydration is present in about $52.5 \%$ and was absent in 47.5\%. Table*8 and table*9 demonstrates the spondylolisthesis is very rare present in about 14 patients $17.5 \%$ and it was absent in 66 patients with $82.5 \%$. The disc bulge is present in 48 patients and its percentage is about 60.0 and is not present in 32 patients and its percentage was about 40. Table*10: the vertebral level L4/L5 is the most frequent site in 41 patients making $(50.6 \%)$ for disk herniation's and disk bulges. Table*11 and table*12 shows that lumbar spondylosis is more common among males who were $49(61.2 \%)$ than females who are 31 and makes $38.8 \%$ of total population taken in this research. It is also demonstrated that lumbar spondylosis is mostly present in old age people.

\section{DISCUSSION}

Generally lower back pain is the most common health issue now days. This problematic issue can be present with various etiologies. In most cases symptom of lower back pain can be non-specific but it can cause serious illness and disability. Prevalence of lower back pain with expanding life span is on the rise. Lumbar spondylosis is the major cause of lower backache worldwide. MRI is the non-invasive and magnificent imaging modality in the advanced world to evaluate underlying changes of spine. Present study was done to evaluate the MRI features of lumbar spine disease that cause pain at lower back. A total of 80 patients with lower back pain were presented to radiology department for MRI scans of lumbosacral spine. Lower backache was present in $83.8 \%$ individuals. In majority of lower back pain cases disc degeneration of lumbar spine was the most frequent cause with $81.2 \%$ of the total population taken in this research. A retrospective study by Verma et al. on 232 individuals determined the frequency of degeneration at lumbar discs as $79.3 \%$ [16]. Uduma et al. presented a review of individuals 48 in number that generated $37.5 \%$ spondylosis with disc hernia $33.3 \%$ [17]

Noha Mohamed Osman et al. conducted a study on 40 patients that showed disc degeneration $42 \%$ with dehydrated discs most frequent at level of L4-L5 and L5-S1 level [13]. Current research ruled out almost similar results that demonstrated the prevalence of different patterns of disc degeneration. Schmidt C. et al. found abnormal image findings in spine of symptomless people ranging $37 \%$ at 20 years of age and 96\% prevalence in people with age of 80 years. Degeneration of disk, loss in disk height, disk herniation and arthritis of facet all are part of normal aging phenomenon [7]. Kenneth M.C Cheung et al. observed the MRIs of 1043 volunteers between ages 18-55 years. This study 
revealed that majority $40 \%$ individuals below age 30 years had lumbar disc degeneration and had high prevalence with increasing age over 90\%. L4-L5 and L5-S1 are the most common affected levels [3]. This research was nearly same in trying to evaluate incidence and different findings on MRI though there is huge difference from present study in the findings possibly because of small patient number.

Mark Buller et al. In 2018 reviewed the degenerative disease of lumbar spine on MRI and found that MRI is the backbone in evaluating reason of pain at low back and the most frequent condition of lumbar spine was degenerative disease [5]. In 2013 Sang Jim Kin et al. demonstrated the abnormal findings of lumbar disc degeneration as bulging of disc, annular fissure and protrusion by obtaining MRIs of young Koreans who were asymptomatic and found L4/L5 and L5/S1 as common lumbar vertebral levels with high prevalence of degeneration [18]. The present study emphasizes the fact that magnetic resonance imaging has a high sensitivity to evaluate degenerative disease of lumbar disease. Features of degeneration that were assessed in our study are degeneration of the lumbar spine disk, modic changes, facetal arthropathy.

A study held by Young et al. described Degeneration of lumbar intervertebral disk as the utmost finding in $91.2 \%$ participant presented along with the complaint of low back pain [19]. Zainab Mohsin et al. worked on the diseases of rheumatism to demonstrate their prevalence and came out with the result that degenerative arthritis as commonly occurring disease with negligent lower back pain having prevalence of $7.35 \%$ and $3.95 \%$ and lumbar spondylosis with $0.7 \%$ prevalence. It was also concluded that diabetes is an associated risk factor in individuals with osteoarthritis and low back pain [20] Young at al. in Malaysia reported disk bulging $40.4 \%$, protrusion and extrusion $50 \%, 19.4 \%$ [19]. In one study less disc bulges and more extrusion and protrusion were reported [16]. A study concluded protrusion $74 \%$, extrusion $28 \%$ and disc bulge $92 \%$. In another study, more bulges, extrusion and protrusion were showed [21].

Lumbar spine region is the area which bears great stress of the whole body along with mechanical stress. Lumbar Disk erosion is traditionally common. Certainty that is substantiated in the current study is where the findings reported that most of people were presented with disk bulge $48(60 \%)$ along with lesions frequent at L4-L5 level $51.2 \%$ whereas in $23.8 \%$ participants lesions was seen at level L5-S1. Participants with lumbar spondylosis are prone to develop serious complications including segmental instability, neural compression, nerve irritation and stenosis. this study reported that the most common complications of disk herniation and disc bulge were compression and impingement $40 \%$ of nerve roots and cauda equina nerves $47.6 \%$ however, Mboka et al. evaluated the compression in spinal nerve root $77 \%$ [21].

The current study was based on cross-sectional and observational information which adds useful information to the research. Various aspects of spine have been seen in present study which can provide high impact on making choice for diagnostic technique to evaluate spine diseases. By this research it will be helpful to evaluate different features of spine degeneration by knowing its clinical symptoms. This research will also help to know the normal aging phenomenon so that people will further enhance their quality of life. A study on lumbar spondylosis was scarce in Pakistan with huge population and lower back pain as the major medical issue. This study will help to further evaluate spine degeneration process and its associated risk factors for future researches in spine.

\section{Conclusions}

In conclusion it is observed that that Low back pain is the most frequent clinical symptom indicative of lumbar spondylosis. Lumbar Disk degenerative disease is usually common in men. The lumbar disc bulges and herniation is common at lumbar disc level L4-L5. Spondylolisthesis is unusual. The most common pattern of disc degeneration involves the disruption of structure causing loss of lordosis. Increasing Age is the most common factor of causing disc degeneration but lumbar spondylosis is also present in young age due to mechanical, nutritional, traumatic, genetic factors.

\section{RECOMMENDATIONS}

It is recommended that to maintain a healthy body weight and mechanics to avoid stressing your spine. For elder patients use of vitamins and supplements can minimize affects leading to disc degenerative changes

\section{Ethical considerations}

The rules and regulations set by the ethical committee of university of Lahore will be followed while conducting the research and the rights of the research participants will be respected

\section{Confidentiality of data}

A written informed consent was taken from all the patients having low back pain. All collected data will be kept confidential for research purpose only.

\section{Informed consent and right to privacy}

Patients were given the right to withdraw their information in any step of data collection. Everything is in confidentiality and all the things that were mentioned in the article are with the permission of every single person which is considered in this article. 


\section{Financial support and conflict of interest}

No financial support and we declared that there is no conflict of study in this research

\section{REFERENCES}

1. Gökçe, E., \& Beyhan, M. (2021). Magnetic resonance imaging findings of redundant nerve roots of the cauda equina. World Journal of Radiology, 13(1), 29.

2. Jensen, R. K., Jensen, T. S., Koes, B., \& Hartvigsen, J. (2020). Prevalence of lumbar spinal stenosis in general and clinical populations: a systematic review and meta-analysis. European Spine Journal, 1-21.

3. Singh, N., Paul, M. Prevalence of Anxiety and Depression among Patients with Chronic Lumbar Spondylosis.

4. Lee, S. Y., Cho, N. H., Jung, Y. O., Seo, Y. I., \& Kim, H. A. (2017). Prevalence and risk factors for lumbar spondylosis and its association with low back pain among rural Korean residents. Journal of Korean Neurosurgical Society, 60(1), 67.

5. Tsujimoto, R., Abe, Y., Arima, K., Nishimura, T., Tomita, M., Yonekura, A., ... \& Osaki, M. (2016). Prevalence of lumbar spondylosis and its association with low back pain among communitydwelling Japanese women. BMC musculoskeletal disorders, 17(1), 1-6.

6. Uehara, K., Akai, M., Doi, T., Oka, H., \& Iwaya, T. (2019). Relationship between X-ray findings of lumbar spondylosis and knee pain. $B M C$ musculoskeletal disorders, 20(1), 1-6.

7. Brinjikji, W., Luetmer, P. H., Comstock, B., Bresnahan, B. W., Chen, L. E., Deyo, R. A., ... \& Jarvik, J. G. (2015). Systematic literature review of imaging features of spinal degeneration in asymptomatic populations. American Journal of Neuroradiology, 36(4), 811-816.

8. Heuck, A., \& Glaser, C. (2014, July). Basic aspects in MR imaging of degenerative lumbar disk disease. In Seminars in musculoskeletal radiology (Vol. 18, No. 03, pp. 228-239). Thieme Medical Publishers.

9. Buller, M. (2018). MRI Degenerative Disease of the Lumbar Spine: A Review. J Am Osteopath Coll Radiol, 7(4), 11-9.

10. Emch, T. M., \& Modic, M. T. (2011). Imaging of lumbar degenerative disk disease: history and current state. Skeletal radiology, 40(9), 11751189.

11. Francis, O. O. (2017). Radiographic lumbar spondylosis: Gender and age group prevalence in Nigeria. Annals of Tropical Medicine and Public Health, 10(5), 1199.
12. Tao, Y., Galbusera, F., Niemeyer, F., Samartzis, D., Vogele, D., \& Wilke, H. J. (2020). Radiographic cervical spine degenerative findings: a study on a large population from age 18 to 97 years. European Spine Journal, 1-13.

13. Osman, N. M., Fawzy, F. M., \& Lateef, H. M. (2017). MRI evaluation of lumbar disc degenerative disease. The Egyptian Journal of Hospital Medicine, 68(2), 1202-1207.

14. Chiba, D., Tsuda, E., Wada, K., Kumagai, G., Sasaki, E., Nawata, A., \& Ishibashi, Y. (2016). Lumbar spondylosis, lumbar spinal stenosis, knee pain, back muscle strength are associated with the locomotive syndrome: rural population study in Japan. Journal of Orthopaedic Science, 21(3), 366372.

15. Kolenkiewicz, M., Włodarczyk, A., \& Wojtkiewicz, J. (2018). Diagnosis and incidence of spondylosis and cervical disc disorders in the university clinical hospital in olsztyn, in years 2011-2015. BioMed research international, 2018.

16. Verma, S. R., Gupta, P. K., Munshi, A., Goyal, P., Verma, S. C., \& Sardana, V. (2011). A Retrospective Analysis of Magnetic Resonance Imaging Findings In 20-40-Year-Old Patients with Low Back Pain. Experience at A Semi Urban Tertiary Healthcare Centre in Northern India. The Internet Journal of Spine Surgery, 6(4), 19378270 .

17. Uduma, F. U., Ongolo, P., Assam, G., Fokam, P., \& Motah, M. (2011). Evaluation of pattern of magnetic resonance images of lumbo-sacral spine in cameroon-a pioneer study. Glob J Med Res, 11, $30-41$.

18. Kim, S. J., Lee, T. H., \& Lim, S. M. (2013). Prevalence of disc degeneration in asymptomatic korean subjects. Part 1: lumbar spine. Journal of Korean Neurosurgical Society, 53(1), 31.

19. Yong, P. Y., Alias, N. N. A., \& Shuaib, I. L. (2003). Correlation of clinical presentation, radiography, and magnetic resonance imaging for low back pain-A preliminary survey. Journalhong kong college of radiologists, 6, 144-151.

20. Mohsin, Z., Asghar, A. A., Faiq, A., Khalid, I., U1Haque, I., Rehman, S., ... \& Safri, M. (2018). Prevalence of rheumatic diseases in a tertiary care hospital of Karachi. Cureus, 10(6).

21. Jacob, M. (2011). Pattern of spine degenerative disease among patients referred for lumbar magnetic resonance imaging at Muhimbili National Hospital, Dar es salaam, Tanzania March-September-2010 (Doctoral dissertation, Muhimbili University of Health and Allied Sciences).

Cite This Article: Maha Munir Mir et al (2021). Prevalence and Radiological Evaluation of Lumbar Spondylosis on Magnetic Resonance Imaging. EAS J Radiol Imaging Technol, 3(2), 57-65. 